\title{
A MOORA based fuzzy multi-criteria decision making approach for supply chain strategy selection
}

\author{
Balaram Dey $^{{ }^{*}}$, Bipradas Bairagi ${ }^{\mathrm{a}}$, Bijan Sarkar ${ }^{\mathrm{b}}$ and Subir Sanyal ${ }^{\mathrm{b}}$
}

${ }^{a}$ Department of Production Engineering, Haldia Institute of Technology, Haldia, W. B., India bDepartment of Production Engineering, Jadavpur University, Kolkata, India

\begin{tabular}{l}
\hline A R T I C L E I N F O \\
\hline Article history: \\
Received 25 October 2011 \\
Received in revised form \\
November, 2, 2011 \\
Accepted February, 32012 \\
Available online \\
16 February 2012 \\
\hline Keywords: \\
Supply chain \\
Warehouse location selection \\
Vendor selection \\
Fuzzy multi-criteria decision \\
making \\
MOORA
\end{tabular}
A B S T R A C T

To acquire the competitive advantages in order to survive in the global business scenario, modern companies are now facing the problems of selecting key supply chain strategies. Strategy selection becomes difficult as the number of alternatives and conflicting criteria increases. Multi criteria decision making (MCDM) methodologies help the supply chain managers to take a lead in a complex industrial set-up. The present investigation applies fuzzy MCDM technique entailing multi-objective optimization on the basis of ratio analysis (MOORA) in selection of alternatives in a supply chain. The MOORA method is utilized to three suitable numerical examples for the selection of supply chain strategies (warehouse location selection and vendor/supplier selection). The results obtained by using current approach almost match with those of previous research works published in various open journals. The empirical study has demonstrated the simplicity and applicability of this method as a strategic decision making tool in a supply chain.

\section{Introduction}

Companies today are often presented with a number of supply chain strategies. Better decision making for aligning the right strategies with its needs results in improving efficiency; reduce costs within a supply chain. Supply chain is a network of organizations involved through upstream (supplier), midstream (manufacturer) and downstream (distributor, retailer) linkages in different processes and activities (Lee \& Billington, 1992) which produce value in the form of products and services to satisfy customers. The objective of a supply chain is to maximize the value generated which is strongly correlated with supply chain profitability. The design, planning and operation of a supply chain have a strong impact on the overall profitability and success of an organization. The performance of a typical supply chain mainly depends upon the parameters such as inventory, transportation, facilities and information. Similarly, supplier selection is a fundamental issue of supply chain area which heavily contributes to the overall supply chain performance (Sanayei et al., 2010).

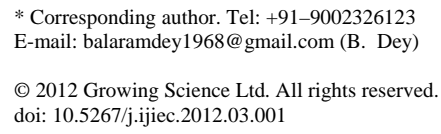


In a supply chain design, the location of facilities is one of the most critical decisions. To optimize supply chain network, facilities such as factories, warehouses, distribution centers (DCs) and retail outlets must be strategically located (Coyle et al., 2003; Simchi-Levi et al., 2003). Owing to the strategic nature of the warehouse location selection, the decisions are made by a committee comprising of high level managers of the organization along with external consultants. The committee chooses various attributes in order to select possible warehouse locations. Some authors considered availability of labor, closeness to markets and customers, availability of suppliers, and even social issues as the potential attributes for the warehouse location selection (Heizer \& Render, 2004; Stevenson, 2005). The selection attributes can be broadly classified into three categories (Liang \& Wang, 1991) such as critical, objective and subjective attributes. The subjective attributes are assessed by human experience and perception, which is naturally associated with imprecision, vagueness, ambiguity and deserves the application of fuzzy multiple criteria decision-making (FMCDM).

Vendor/Supplier selection has a strategic dimension on any company's competitive priorities, such as price, quality, delivery, services, technical capability and improvement. The decision-making process is highly complex and involves imprecise information. A vendor selection problem usually involves more than one criterion and they are generally conflicting to each other. That is why fuzzy multi criteria decision making (FMCDM) has a role to play in order to select the alternative vendors. Supplier selection process is one of the most important components of production and logistics management for many companies. Selection of a wrong supplier could be enough to upset the company's financial and

operational position. Selecting the right suppliers significantly reduces purchasing costs, improves competitiveness in the market and enhances end user satisfaction.

Multiple criteria decision making (MCDM) is the approach of ranking and selection of alternatives from a set of feasible alternatives. MCDM approach is divided into two categories (Wang \& Lee, 2007) viz. classical MCDM (Feng \& Wang, 2000), and Fuzzy Multiple Criteria Decision Making (FMCDM) (Wang et al., 2003). In classical MCDM decisions are made under certainty on the basis of objective criteria (quantitative) (Zeleny, 1982). The MCDM problems are solved using various techniques or tools include the total sum (TS), the simple additive weighting (SAW) method, the AHP, the data development analysis (DEA), the outranking approaches ELECTRE and PROMETHEE and the TOPSIS(techniques for order preference similarity to ideal solution) method (Hwang \& Yoon, 1981). Under many circumstances where performance ratings and weights cannot be given precisely, the fuzzy set theory is introduced to model the uncertainty of human judgments, perception etc. and such problem is known as fuzzy multiple criteria decision making (FMCDM).

The objective of the present paper is to enhance evaluation and selection methodology and to recommend an alternative approach by applying multi-objective optimization on the basis of ratio analysis (MOORA) method. This paper attempts to explore the applicability of MOORA, an MCDM approach to solve different selection problems in supply chain environment. Three illustrative examples consisting of warehouse location selection and vendor/supplier selection are considered in this paper. The outcome of this algorithm has also been compared with those of some works performed by various earlier researchers on the same problems.

\section{Literature review}

A survey of previous literatures reveals a lot of published works on the selection of warehouse location for different supply chain configurations. Shuo et al. (2008) presented fuzzy simple additive weighting method for solving facility location selection problems, which is a new FMADM approach. The work is unable to handle problems related to multi facility location. Chen et al. (2007) presented a two-phase fuzzy decision-making method for locating warehouse in a supply chain. Their paper investigated the simultaneous optimization of multiple conflict objectives problem in a typical supply chain network with market demand uncertainty. Liang and Wang (1991); Kuo et al. (1999) applied fuzzy set theory (FST) and its extended version to solve facility location selection problems. Liang (1999) created a fuzzy 
multiple attribute decision-making method to identify the optimal alternative based on ideal and antiideal point concepts. Kahraman et al. (2003) tried to solve facility location problems using four different fuzzy multi-attribute group decision-making (FMAGDM) approaches considering both quantitative as well as qualitative criteria. They compared the approaches in terms of computational complexity and found fuzzy AHP as the most complex among all. Chen (2001) developed a new FMADM approach for distribution centre (DC) location selection problem based on a stepwise ranking procedure. Chu (2002) presented a fuzzy technique for order preference by similarity to ideal solution (TOPSIS) model to solve the facility location selection problem under group decision-making. Guneri et al. (2009) developed a fuzzy analytical network process (ANP) to shipyard location selection. Li and Kuo (2008) developed an enhanced fuzzy neural network (EFNN) based on decision support system for managing automobile spares inventory in a central warehouse.

Chun and Kun (2009) utilized the dynamic product-process change matrix as a lens/map for helping managers to link the selection criteria with the requirements of operations strategies for facility location selection. Peter and Marco (2009) explored the current literature on the overall methodology of warehouse design together with the literature on tools and techniques used for specific areas of analysis. Bhattacharya et al. (2004) proposed a method for selecting plant location under MCDM environment with certainty. Emanuel et al. (2009) proposed a physical programming (PP) methodology to enable a decision maker to consider multiple criteria (i.e., cost, customer service and intangible benefits). An extensive review was carried out by (Jinxiang et al., 2007) on warehouse operation planning problems which were classified according to the basic warehouse functions, i.e., receiving, storage, order picking, and shipping.

De Boer et al. (2001) provided a comprehensive review of the literature concerning supplier selection. Jian et al. (2008) proposed integrated fuzzy multiple criteria decision making (FMCDM) method addressing the interrelationship among the sub criteria for the vendor selection problem. Kumar et al. (2004) presented a fuzzy goal programming approach to solve the vendor selection problem with three objectives. Shyur and Shih (2006) developed a hybrid MCDM method for strategic vendor selection by using both the ANP and TOPSIS methods. Chen et al. (2006) developed a hierarchy multiple criteria decision-making model based on fuzzy set theory to deal with the supplier selection problems. Mikhailov (2002) proposed the fuzzy AHP method to determine the weight of each criterion and to score each alternative for each criterion.

The remainder of this paper is organized as follows. Section 3 presents the fuzzy set theory in brief. This is followed by MOORA algorithm in section 4. In the section 5, suitable examples are- furnished and solved. Section 6 presents some significant concluding remarks on the applied methodology.

\section{Fuzzy set theory}

Zadeh (1965) pioneered the use of fuzzy set theory to address the problems of tackling the vagueness in information and the fuzziness in human perception. In a universe of discourse $\mathrm{X}$, a fuzzy subset $\tilde{A}$ of $\mathrm{X}$ is defined with a membership function $\mu_{\tilde{A}}(x)$ that maps each element $\mathrm{X}$ in $\mathrm{X}$ to a real number in the interval $[0,1]$. The function value of $\mu_{\tilde{A}}(x)$ signifies the grade of membership of $\mathrm{x}$ in $\tilde{A}$. A triangular fuzzy number (TFN) $\tilde{A}$ can be defined as a triplet (a, b, c) and the membership function is defined (Dubois and Prade 1978, Keufmann and Gupta 1991) as shown by Eq.1.

$$
\mu_{\tilde{A}}(x)=\left\{\begin{array}{cc}
\frac{(x-a)}{(b-a)}, & a \leq x \leq b, \\
\frac{(c-x)}{(c-b)}, & b \leq x \leq c \\
0, & \text { otherwise }
\end{array}\right.
$$


The concept of combining the fuzzy set theory and MCDM is referred to as fuzzy MCDM. In fuzzy MCDM, performance rating of alternatives and weights of criteria are expressed in linguistic terms (Linguistic variables). Linguistic variables are then transformed into either triangular, trapezoidal fuzzy numbers or range of fuzzy numbers.

\section{The MOORA method}

Multi-objective optimization on the basis of ratio analysis (MOORA), also known as multi-criteria or multi attribute optimization is the process of simultaneously optimizing two or more conflicting attributes (objectives) subject to certain constraints. This method has wide range of applications to make decisions in conflicting and complex area of supply chain environment. Warehouse location selection, supplier selection, product and process design selection etc. wherever optimal decisions need to be taken, MOORA can be applied. Decision making is the process of defining the decision goals, gathering relevant information and selecting the optimal alternative (Hees \& Sicihano, 1996). While decision making in a supply chain environment the attributes (objectives) must be quantified and the fuzziness of linguistic variables of the attributes has to be defuzzified into a crisp value. The outcomes can be measured for every decision alternatives. Objective outcomes provide the basis of comparison of choices and ultimately lead to the selection of best one. Hence, MOORA method can be effectively applied as an appropriate tool for the ranking and selection of the alternatives among various set of available options.

Brauers (2004) first introduced the MOORA method in order to solve various complex and conflicting decision making problems. The MOORA method starts with a decision matrix as shown by Eq. (2). The decision matrix represents the performance measures of alternatives with respect to various criteria (objective). Performance ratings under objective criteria are expressed by crisp (specific) values but performance ratings under subjective criteria are expressed by linguistic variables due to vagueness, imprecision, indistinctness and ambiguity. The words or phrases like 'good', 'very good', 'medium', 'poor', 'very poor' etc. are called linguistic variables which are measured by human perception, feelings, experience etc. A decision matrix with $\boldsymbol{m}$ number of alternatives $\left(A_{1}, \ldots, A_{i}, \ldots, A_{m}\right)$, $\boldsymbol{n}$ number of criteria $\left(\mathrm{C}_{1}, \ldots, \mathrm{C}_{\mathrm{j}}, \ldots, \mathrm{C}_{\mathrm{n}}\right)$ and $\boldsymbol{m} \boldsymbol{x \boldsymbol { n }}$ number of performance ratings $\left(x_{11 k}, \ldots, x_{i j k}, \ldots, x_{m n k}\right)$ is formed as follows.

$$
\begin{aligned}
& \begin{array}{llllll}
\mathrm{C}_{1} & \ldots & \mathrm{C}_{\mathrm{j}} & \ldots & \mathrm{C}_{\mathrm{n}}
\end{array}
\end{aligned}
$$

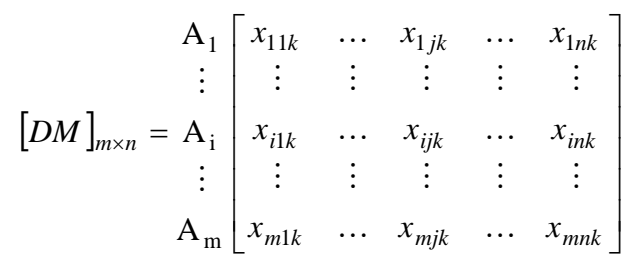

where $x_{i j k}$ is the performance rating of $i^{\text {th }}$ alternative for $j^{\text {th }}$ criterion given by $k^{\text {th }}$ decision maker and expressed as $x_{i j k}=\left(a_{i j k}, b_{i j k}\right)$ or $x_{i j k}=\left(a_{i j k}, b_{i j k}, c_{i j k}\right)$. These fuzzy numbers are defuzzified using relation $x_{i j k}^{\prime}=\left(\sum a_{i j k}\right) / 2$ and $x_{i j k}^{\prime}=\left(\sum a_{i j k}\right) / 3$ in case of range of fuzzy values and triangular fuzzy numbers, respectively. Average rating of alternatives is computed by the formula $\bar{x}_{i j}=\frac{1}{K}\left(\sum_{k=1}^{K} x_{i j k}\right)$ where $1 \leq k \leq K$, and $K$ is the number of decision makers.

Brauers and Zavadskas (2006) described MOORA as a ratio system in which each response of an alternative to an objective is compared to a denominator which is representative of all the alternatives concerning that particular objective. For this denominator the square root of the sum of squares of each 
alternative per objective is chosen (Van Delft \& Nijkamp, 1977). Brauers et al. (2008) considered various ratio systems such as Stopp ratio, Weitendorf ratio, total ratio, Korth ratio, Scharlig ratio, Juttler ratio etc. and concluded that for this denominator, the best choice is the square root of the sum of squares of each alternative per criterion. This ratio system is expressed by Eq. (3).

Normalization of average rating of each alternative with respect to each subjective as well as objective criterion is determined using following Eq. (3)

$$
\bar{x}_{i j}^{N}=\bar{x}_{i j} /\left[\sum_{i=1}^{m} \bar{x}_{i j}^{2}\right]^{1 / 2}, \quad \mathrm{j}=1,2 \ldots \mathrm{n}
$$

where $\bar{x}_{i j}^{N}$ is a dimensionless number which belongs to interval $[0,1]$ representing the normalized performance of $i^{\text {th }}$ alternative on the $j^{\text {th }}$ criteria. In MOORA, the normalized performance measures are added in case of maximization (for beneficial criteria) and subtracted in case of minimization(for nonbeneficial criteria).Then the optimization problem(composite score)becomes

$$
Z_{i}=\sum_{j=1}^{b} x_{i j}^{N}-\sum_{j=b+1}^{n} x_{i j}^{N},
$$

where $b$ is the number of criteria to be maximized, (n-b) is the number of criteria to be minimized, and $z_{i}$ is the normalized composite score of $i^{\text {th }}$ alternative with respect to all the criteria.

It has been noticed that some attributes are more important than the others (Brauers et al, 2009) .When the weights of the attributes are different, the optimization problem (composite score) becomes

$$
z_{i}=\sum_{j=1}^{b} w_{j} \otimes x_{i j}^{N}-\sum_{j=b+1}^{n} w_{j} \otimes x_{i j}^{N} \quad \mathrm{j}=1,2, \ldots \mathrm{n}
$$

where $w_{j}$ is the weight of $j^{\text {th }}$ criterion. The $z_{i}$ (composite score) may be positive or negative depending upon the totals of its maxima (beneficial criteria) and minima (non-beneficial criteria) in the decision matrix. The ranking of the alternatives is determined on the basis of the descending order of the composite score. The best alternative has the highest $z_{i}$ (composite score) value and the worst alternative has lowest $z_{i}$ (composite score) value.

\section{Illustrative example}

Three examples on supply chain strategies are extracted from various open journals in order to demonstrate the applicability of MOORA method in FMCDM environment.

\subsection{Warehouse location selection (Example 1)}

Warehouse location selection is very crucial in any supply chain configuration in order to improve its performance. Warehouse location is a long-term decision and is influenced by many quantitative and qualitative criteria. The present example is cited from Chen (2001). In the problem, a decision making committee is formed consisting of three members viz. $\mathrm{D}_{1}, \mathrm{D}_{2}, \mathrm{D}_{3}$. After initial screening the committee preliminarily considers three alternatives viz. $A_{1}, A_{2}$ and $A_{3}$. The committee considers five selection criteria as investment cost $\left(C_{1}\right)$, expansion possibility $\left(C_{2}\right)$, availability of material $\left(C_{3}\right)$, human resource $\left(\mathrm{C}_{4}\right)$ and closeness to demand market $\left(\mathrm{C}_{5}\right)$. The investment cost criterion is to be minimized (nonbeneficial criterion) whereas all the other criteria expansion possibility, availability of material, human resource and closeness to demand market are to be maximized (beneficial criteria). The fuzzy decision matrix comprising of performance measures (average rating) of the alternatives with respect to all criteria is shown in Table 1. The performance ratings of alternatives are then defuzzified and shown in 
Table 2. In order to find the normalized performance rating, the best ratio system is chosen. For this best ratio system, the denominator is the square root of the sum of squares of each alternative warehouse per criterion as shown in Table 2. The normalized values of performance rating of each alternative with respect to all subjective as well as objective criteria are calculated by using Eq.(3) and shown in Table 3. Chen (2001) considered the importance of weight of each criterion in terms of linguistic variables as triangular fuzzy numbers. Defuzzified and normalized weight of each criterion is shown in Table no.4. Composite Score of alternatives are then calculated by using Eq. (5) as shown in Table 5. Fig. 1 depicts composite score of alternative warehouse locations. All the values of the composite score are positive in nature as the total number of beneficial criteria is larger than the non-beneficial criteria. The final ranking of the alternatives is determined on the basis of the descending order values of composite score. The ranking of warehouses according to proposed method is $A_{2} \succ A_{3} \succ A_{1}$ as shown in Table 5. The best warehouse location is $A_{2}$. Table 6.shows the comparative ranking of warehouse locations obtained by applying proposed method with those of various other papers available in the open journals. Fig. 2 depicts a comparison of ranking of alternatives between MOORA (applied method) and the integrated fuzzy MCDM method applied in previous research work (Chen, 2001).

Table 1

Decision matrix (Average performance score)

\begin{tabular}{|c|c|c|c|c|c|}
\hline $\begin{array}{l}\text { Alternatives } \\
\qquad\left(A_{i}\right)\end{array}$ & $\begin{array}{l}\mathrm{C}_{1} \text { (Investment } \\
\text { cost) } \\
(\mathrm{Min})(-) \\
\end{array}$ & $\begin{array}{c}\mathrm{C}_{2} \text { ( Expansion } \\
\text { possibility) (Max) } \\
(+) \\
\end{array}$ & $\begin{array}{c}\mathrm{C}_{3} \text { (Availability of } \\
\text { material) }(\text { Max) } \\
(+)\end{array}$ & $\begin{array}{c}\mathrm{C}_{4}(\text { Human } \\
\text { resource) } \\
(\mathrm{Max})(+) \\
\end{array}$ & $\begin{array}{c}\mathrm{C}_{5} \text { (Closeness to } \\
\text { demand market)(Max) } \\
(+)\end{array}$ \\
\hline$A_{1}$ & 7 million & $(6.3,8,9)$ & $(5.7,7.7,9)$ & $(7.7,9.3,10)$ & $(3,5,7)$ \\
\hline $\mathrm{A}_{2}$ & 4 million & $(9,10,10)$ & $(7,9,10)$ & $(7,9,10)$ & $(5.7,7.7,9)$ \\
\hline $\mathrm{A}_{3}$ & 5 million & $(7,9,10)$ & $(7,9,10)$ & $(8.3,9.7,10)$ & $(7,9,10)$ \\
\hline
\end{tabular}

Table 2

Defuzzified performance score of alternatives with their sums of square and square root values

\begin{tabular}{llllll}
\hline Alternatives & $\mathrm{C}_{1}(-)$ & $\mathrm{C}_{2}(+)$ & $\mathrm{C}_{3}(+)$ & $\mathrm{C}_{4}(+)$ & $\mathrm{C}_{5}(+)$ \\
\hline $\mathrm{A}_{1}$ & 7 & 7.77 & 7.46 & 9.00 & 5.00 \\
$\mathrm{~A}_{2}$ & 4 & 9.67 & 8.67 & 8.67 & 7.46 \\
$\mathrm{~A}_{3}$ & 5 & 8.67 & 8.67 & 9.33 & 8.67 \\
Sum of Squares & 90.0601 & 228.9169 & 205.9225 & 243.36 & 155.7504 \\
Square Roots & 9.49 & 15.13 & 14.35 & 15.60 & 12.48 \\
\hline
\end{tabular}

Table 3

Normalized and defuzzified rating of alternatives

\begin{tabular}{llllll}
\hline Alternatives & $\mathrm{C}_{1}(-)$ & $\mathrm{C}_{2}(+)$ & $\mathrm{C}_{3}(+)$ & $\mathrm{C}_{4}(+)$ & $\mathrm{C}_{5}(+)$ \\
\hline $\mathrm{A}_{1}$ & 0.7376 & 0.5135 & 0.5198 & 0.5764 & 0.4006 \\
$\mathrm{~A}_{2}$ & 0.4215 & 0.6391 & 0.6042 & 0.5557 & 0.5977 \\
$\mathrm{~A}_{3}$ & 0.5269 & 0.5730 & 0.6042 & 0.5980 & 0.6947 \\
\hline
\end{tabular}

Table 4

Weights of criteria

\begin{tabular}{llllll}
\hline Weight & $\mathrm{C}_{1}(-)$ & $\mathrm{C}_{2}(+)$ & $\mathrm{C}_{3}(+)$ & $\mathrm{C}_{4}(+)$ & $\mathrm{C}_{5}(+)$ \\
\hline Fuzzy weight and & $(.83, .97,1.0)$ & $(.7, .9,1.0)$ & $(.57, .77, .93)$ & $(.5, .7, .9)$ & $(.7, .9,1.0)$ \\
$\begin{array}{l}\text { Defuzzified } \\
\text { Normalized weight }\end{array}$ & & 0.2263 & 0.1835 & 0.1698 & 0.2101 \\
\hline $\begin{array}{l}\text { Source: Chen (2001) } \\
\end{array}$ & & & & \\
\hline
\end{tabular}


Table 5

Composite Score of alternatives and their ranking

\begin{tabular}{lllll}
\hline Alternatives & Benefit value & Non-Benefit value & Composite Score & Ranking \\
\hline $\mathrm{A}_{1}$ & 0.3853 & 0.1669 & 0.2184 & 3 \\
$\mathrm{~A}_{2}$ & 0.4650 & 0.0953 & 0.3697 & 1 \\
$\mathrm{~A}_{3}$ & 0.4787 & 0.1192 & 0.3595 & 2 \\
\hline
\end{tabular}

\section{Table 6}

Comparative ranking of warehouse locations among various methods

\begin{tabular}{lll}
\hline Alternatives & Integrated fuzzy MCDM method Chen (2001) & MOORA(Applied method) \\
\hline$A_{1}$ & 3 & 3 \\
$A_{2}$ & 1 & 1 \\
$A_{3}$ & 2 & 2 \\
\hline
\end{tabular}

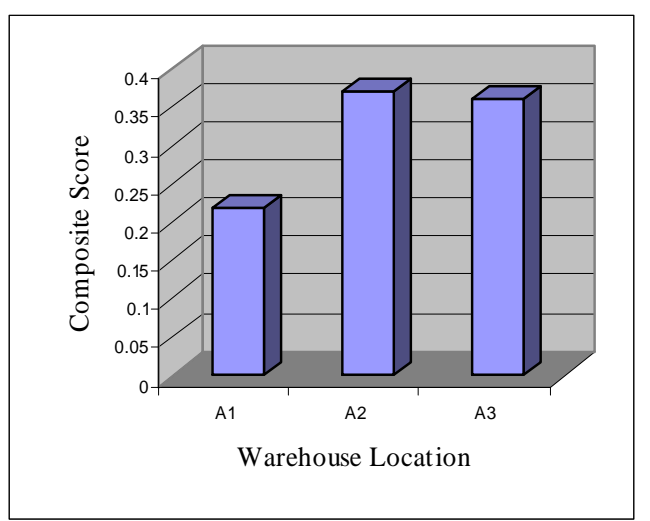

Fig. 1 Composite score of warehouse location for example 1

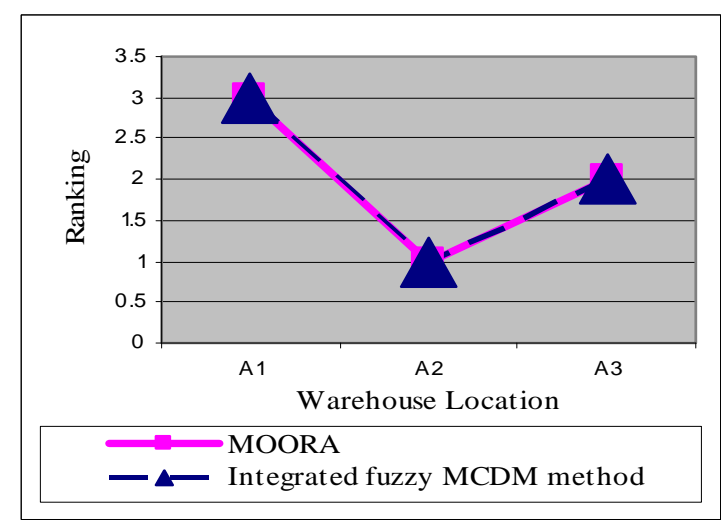

Fig. 2 Comparative ranking of warehouse location obtained by various methods for example 1

\subsection{Vendor selection (Example 2)}

The selection of right vendor is one of the most important functions of any company's purchasing department and having strategic impact on the overall profitability of that organization. The vendor selection problem is an unstructured, complicated and multi criteria decision making problem. The method MOORA is applied to solve a vendor selection problem cited from Yang et al. (2008). Five vendors $\left(\mathrm{V}_{1}, \mathrm{~V}_{2}, \mathrm{~V}_{3}, \mathrm{~V}_{4}\right.$ and $\left.\mathrm{V}_{5}\right)$ are screened out for evaluation purpose. Many studies have pointed out that the key is to set effective selection criteria for the vendor selection problem. The list of criteria and sub-criteria involved in this vendor selection problem are listed in Table 7.Out of all these criteria, quality $\left(\mathrm{C}_{1}\right)$, supply chain support $\left(\mathrm{C}_{3}\right)$, technology $\left(\mathrm{C}_{4}\right)$ and the sub-criteria under them are the beneficial factors and hence are to be maximized. Price and terms $\left(\mathrm{C}_{2}\right)$ and its various sub-criteria are the non-beneficial factors which are to be minimized. Table 7 also represents the normalized weights of all sub-criteria. Table 8 gives the fuzzy performance score of all vendors with respect to all sub-criteria. The performance score of all the alternative vendors are defuzzified as shown in Table 9. In order to find the normalized performance rating, the best ratio system is chosen. For this best ratio system, the denominator is the square root of the sum of squares of each alternative vendor per criterion as shown in Table 9. The normalized values of performance rating of each alternative vendor with respect to all sub-criteria are calculated by using Eq. (3) and shown in Table 10.

Composite score of alternative vendors are then calculated by using Eq. (5) as shown in Table 10. Fig. 3 depicts composite score of alternative vendors. All the values of the composite score are positive in nature as the total number of beneficial criteria is larger than the non-beneficial criteria. The final 
ranking of the alternatives is determined on the basis of the descending order values of composite score. The ranking of alternative vendors according to the MOORA method is $V_{2} \succ V_{1} \succ V_{5} \succ V_{4} \succ V_{3}$ as shown in Table 11. The best vendor is $V_{2}$. Yang et al. (2008) solved the same vendor selection problem by integrated fuzzy MCDM technique and observed the ranking of alternative vendors as $V_{2} \succ V_{3} \succ V_{1} \succ V_{5} \succ V_{4}$. While solving the same problem using traditional AHP method, the ranking of the alternative vendors obtained as $V_{2} \succ V_{1} \succ V_{3} \succ V_{5} \succ V_{4}$. Fig. 4 shows a comparative ranking of alternative vendors among MOORA and the methods applied in previous research works. The ranking of the vendors from these three methods reveal that the best vendor $\left(V_{2}\right)$ remains same whereas the ranking of the intermediate vendors were different. Different methods resulted in different ranking of the intermediate vendors. A comparative ranking analysis among these methods is made and shown in Table 12.

\section{Table 7}

Criteria and sub-criteria for the vendor selection and normalized sub- criteria weights

\begin{tabular}{ll}
\hline Criteria and sub-criteria & Normalized sub- criteria weights \\
\hline Quality $\left(\mathrm{C}_{1}\right)(\mathrm{Max})(+)$ & 0.1198 \\
- Quality performance $\left(\mathrm{C}_{11}\right)(+)$ & 0.1104 \\
- Quality containment\& VDCS feed back $\left(\mathrm{C}_{12}\right)(+)$ & 0.1227 \\
Price and terms $\left(\mathrm{C}_{2}\right)(\mathrm{Min})(-)$ & 0.0686 \\
- Price $\left(\mathrm{C}_{21}\right)(-)$ & 0.0189 \\
- Terms $\left(\mathrm{C}_{22}\right)(-)$ & 0.0212 \\
- Responsiveness $\left(\mathrm{C}_{23}\right)(-)$ & 0.0144 \\
- Lead time $\left(\mathrm{C}_{24}\right)(-)$ & \\
- VMI/VOI hub set up cost $\left(\mathrm{C}_{25}\right)(-)$ & 0.1153 \\
Supply chain support $\left(\mathrm{C}_{3}\right)(\mathrm{Max})(+)$ & 0.0668 \\
- purchase order reactiveness $\left(\mathrm{C}_{31}\right)(+)$ & 0.0792 \\
- Capacity support \&flexibility $\left(\mathrm{C}_{32}\right)(+)$ & \\
- Delivery/VMI operation $\left(\mathrm{C}_{33}\right)(+)$ & 0.0954 \\
Technology $\left(\mathrm{C}_{4}\right)(\mathrm{Max})(+)$ & 0.0998 \\
- Technical support $\left(\mathrm{C}_{41}\right)(+)$ & 0.0675 \\
- Design involvement $\left(\mathrm{C}_{42}\right)(+)$ & \\
- ECN/PCN process $\left(\mathrm{C}_{43}\right)(+)$ & \\
\hline Source:Yang al $(2008)$ &
\end{tabular}

Source:.Yang et al. (2008)

\section{Table 8}

Fuzzy performance score of vendors for all sub-criteria

\begin{tabular}{|c|c|c|c|c|c|}
\hline Vendors & $\begin{array}{l}\text { Sub -criteria } \\
\mathrm{C}_{11}(+)\end{array}$ & $\mathrm{C}_{12}(+)$ & $\mathrm{C}_{21}(-)$ & $\mathrm{C}_{22}(-)$ & $\mathrm{C}_{23}(-)$ \\
\hline$\overline{V_{1}}$ & $(2.94,4.12,5.81)$ & $(4.37,6.11,7.71)$ & $(4.25,5.81,7.24)$, & $(3.87,5.25,6.98)$ & $(3.66,5.35,6.66)$ \\
\hline $\mathrm{V}_{2}$ & $(3.88,5.51,7.08)$ & $(4.82,6.02,7.66)$ & $(4.11,5.77,7.29)$, & $(5.25,6.91,8.30)$ & $(3.97,5.69,7.17)$ \\
\hline $\mathrm{V}_{3}$ & $(4.02,5.84,7.22)$ & $(2.22,3.42,5.06)$ & $(5.07,6.72,7.82)$ & $(3.99,5.54,6.84)$ & $(3.21,4.81,6.17)$ \\
\hline $\mathrm{V}_{4}$ & $(1.90,2.93,4.58)$ & $(2.39,3.94,5.69)$ & $(1.86,3.33,5.00)$ & $(1.30,2.46,4.14)$ & $(2.45,3.66,5.53)$ \\
\hline $\mathrm{V}_{5}$ & $(3.86,5.68,7.09)$ & $(2.29,3.81,5.49)$ & $(1.34,2.04,3.56)$ & $(2.90,4.28,5.63)$ & $(2.88,4.19,5.58)$ \\
\hline & $\mathrm{C}_{24}(-)$ & $\mathrm{C}_{25}(-)$ & $\mathrm{C}_{31}(+)$ & $\mathrm{C}_{32}(+)$ & $\mathrm{C}_{33}(+)$ \\
\hline $\mathrm{V}_{1}$ & $(4.47,6.14,7.53)$ & $(5.14,6.83,8.33)$ & $(2.67,4.44,6.02)$ & $(5.75,6.96,8.55)$ & $(3.74,5.40,6.92)$ \\
\hline $\mathrm{V}_{2}$ & $(6.57,7.91,8.86)$ & $(4.56,6.18,7.71)$ & $(5.23,6.78,8.14)$ & $(5.18,6.72,8.18)$ & $(4.33,6.09,7.66)$ \\
\hline $\mathrm{V}_{3}$ & $(2.46,3.76,5.34)$ & $(2.16,3.70,5.23)$ & $(2.52,4.12,5.94)$ & $(3.14,4.52,6.25)$ & $(2.76,4.42,5.88)$ \\
\hline $\mathrm{V}_{4}$ & $(2.04,3.43,5.02)$ & $(3.89,5.19,7.05)$ & $(2.77,4.09,5.81)$ & $(2.71,4.24,5.91)$ & $(1.95,3.31,4.50)$ \\
\hline$V_{5}$ & $(4.43,5.64,7.49)$ & $(2.75,4.20,5.47)$ & $(2.69,4.29,5.78)$ & $(3.62,5.38,6.98)$ & $(2.61,4.08,5.71)$ \\
\hline & $\mathrm{C}_{41}(+)$ & $\mathrm{C}_{42}(+)$ & $\mathrm{C}_{43}(+)$ & & \\
\hline $\mathrm{V}_{1}$ & $(1.86,3.18,4.85)$ & $(4.88,6.42,7.83)$ & $(3.22,5.18,6.85)$ & & \\
\hline $\mathrm{V}_{2}$ & $(4.33,5.93,7.44)$ & $(6.36,7.85,8.91)$ & $(4.73,6.36,7.79)$, & & \\
\hline $\mathrm{V}_{3}$ & $(4.02,5.53,6.83)$ & $(2.52,3.98,5.68)$ & $(2.84,4.14,5.88)$ & & \\
\hline $\mathrm{V}_{4}$ & $(2.39,3.59,5.46)$ & $(2.24,3.93,5.43)$ & $(3.49,5.07,6.50)$ & & \\
\hline $\mathrm{V}_{5}$ & $(2.43,4.07,5.55)$ & $(1.84,2.71,4.36)$ & $(2.24,3.37,4.88)$ & & \\
\hline
\end{tabular}


Table 9

Defuzzified performance score of alternatives with their sums of square and square root values

\begin{tabular}{|c|c|c|c|c|c|c|c|c|c|c|c|c|c|}
\hline & $\mathrm{C}_{11}(+)$ & $\mathrm{C}_{12}(+)$ & $\mathrm{C}_{21}(-)$ & $\mathrm{C}_{22}(-)$ & $\mathrm{C}_{23}(-)$ & $\mathrm{C}_{24}(-)$ & $\mathrm{C}_{25}(-)$ & $\mathrm{C}_{31}(+)$ & $\mathrm{C}_{32}(+)$ & $\mathrm{C}_{33}(+)$ & $\mathrm{C}_{41}(+)$ & $\mathrm{C}_{42}(+)$ & $\mathrm{C}_{43}(+)$ \\
\hline $\mathrm{V}_{1}$ & 4.289 & 6.065 & 5.768 & 5.367 & 5.221 & 6.051 & 6.767 & 4.376 & 7.089 & 5.355 & 3.295 & 6.378 & 5.083 \\
\hline$V_{2}$ & 5.491 & 6.167 & 5.721 & 6.819 & 5.609 & 7.782 & 6.15 & 6.718 & 6.692 & 6.026 & 5.897 & 7.705 & 6.293 \\
\hline$V_{3}$ & 5.692 & 3.568 & 6.534 & 5.459 & 4.73 & 3.854 & 3.693 & 4.196 & 4.635 & 4.353 & 5.46 & 4.06 & 4.288 \\
\hline $\mathrm{V}_{4}$ & 3.136 & 4.006 & 3.395 & 2.633 & 3.88 & 3.494 & 5.377 & 4.224 & 4.287 & 3.253 & 3.812 & 3.868 & 5.022 \\
\hline$V_{5}$ & 5.541 & 3.863 & 2.315 & 4.272 & 4.215 & 5.853 & 4.138 & 4.254 & 5.326 & 4.131 & 4.016 & 2.969 & 3.499 \\
\hline SoS & 121.48 & 118.53 & 125.57 & 130.28 & 113.91 & 158.48 & 143.28 & 118.48 & 163.28 & 111.58 & 106.11 & 140.30 & 121.29 \\
\hline SR & 11.02 & 10.89 & 11.21 & 11.41 & 10.67 & 12.59 & 11.97 & 10.86 & 12.778 & 10.56 & 10.301 & 11.845 & 11.013 \\
\hline
\end{tabular}

SoS=Sum of squares, $\mathrm{SR}=$ Square root

Table 10

Normalized defuzzified performance score of alternatives and normalized weights of sub criteria

\begin{tabular}{|c|c|c|c|c|c|c|c|c|c|c|c|c|c|}
\hline & $\mathrm{C}_{11}(+)$ & $\mathrm{C}_{12}(+)$ & $\mathrm{C}_{21}(-)$ & $\mathrm{C}_{22}(-)$ & $\mathrm{C}_{23}(-)$ & $\mathrm{C}_{24}(-)$ & $\mathrm{C}_{25}(-)$ & $\mathrm{C}_{31}(+)$ & $\mathrm{C}_{32}(+)$ & $\mathrm{C}_{33}(+)$ & $\mathrm{C}_{41}(+)$ & $\mathrm{C}_{42}(+)$ & $\mathrm{C}_{43}(+)$ \\
\hline$V_{1}$ & 0.3891 & 0.5571 & 0.5147 & 0.4702 & 0.4892 & 0.4806 & 0.5653 & 0.4031 & 0.5548 & 0.5069 & 0.3199 & 0.5385 & 0.4615 \\
\hline $\mathrm{V}_{2}$ & 0.4982 & 0.5665 & 0.5105 & 0.5974 & 0.5255 & 0.6181 & 0.5138 & 0.6189 & 0.5237 & 0.5705 & 0.5725 & 0.6505 & 0.5714 \\
\hline$V_{3}$ & 0.5164 & 0.3277 & 0.5831 & 0.4783 & 0.4432 & 0.3061 & 0.3085 & 0.3866 & 0.3627 & 0.4121 & 0.5301 & 0.3428 & 0.3894 \\
\hline $\mathrm{V}_{4}$ & 0.2845 & 0.368 & 0.303 & 0.2307 & 0.3635 & 0.2775 & 0.4492 & 0.3891 & 0.3355 & 0.308 & 0.3701 & 0.3265 & 0.456 \\
\hline$V_{5}$ & 0.5027 & 0.3548 & 0.2066 & 0.3743 & 0.3949 & 0.4649 & 0.3457 & 0.3919 & 0.4168 & 0.3911 & 0.3899 & 0.2507 & 0.3177 \\
\hline $\mathrm{W}_{\mathrm{i}}$ & 0.1198 & 0.1104 & 0.1227 & 0.0686 & 0.0189 & 0.0212 & 0.0144 & 0.1153 & 0.0668 & 0.0792 & 0.0954 & 0.0998 & 0.0675 \\
\hline
\end{tabular}

\section{Table11}

Composite Scores of alternatives and their ranking

\begin{tabular}{lllll}
\hline Alternative Vendors & Benefit criteria & Non-benefit criteria & Composite Score & Ranking \\
\hline $\mathrm{V}_{1}$ & 0.3007 & 0.123 & 0.1778 & 2 \\
$\mathrm{~V}_{2}$ & 0.3605 & 0.1341 & 0.2264 & 1 \\
$\mathrm{~V}_{3}$ & 0.266 & 0.1237 & 0.1423 & 5 \\
$\mathrm{~V}_{4}$ & 0.2202 & 0.0722 & 0.148 & 4 \\
$\mathrm{~V}_{5}$ & 0.2419 & 0.0733 & 0.1686 & 3 \\
\hline
\end{tabular}

Table 12

Comparative ranking of vendors among various methods

\begin{tabular}{llll}
\hline Alternative Vendors & *Traditional AHP method & $\begin{array}{l}\text { *Integrated } \\
\text { MCDM technique }\end{array}$ & fuzzy \\
& & 3 & 2 \\
\hline $\mathrm{V}_{1}$ & 2 & 1 & 1 \\
$\mathrm{~V}_{2}$ & 1 & 2 & 5 \\
$\mathrm{~V}_{3}$ & 3 & 5 & 4 \\
$\mathrm{~V}_{4}$ & 5 & 4 & 3 \\
$\mathrm{~V}_{5}$ & 4 & & \\
\hline
\end{tabular}

*(Source: Yang et al. (2008)

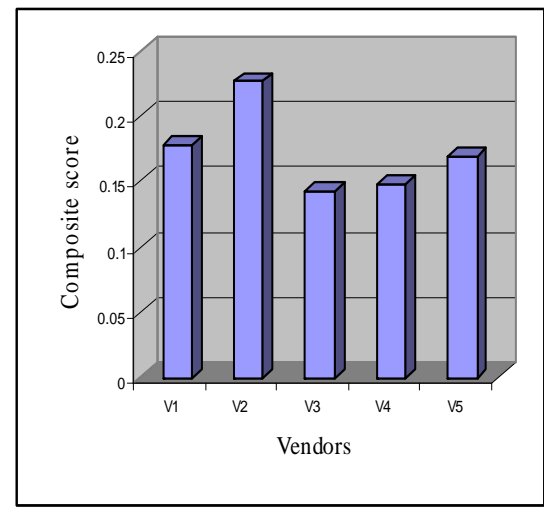

Fig. 3. Composite score of vendors for example 2 Fig. 4. Comparative ranking of vendors obtained

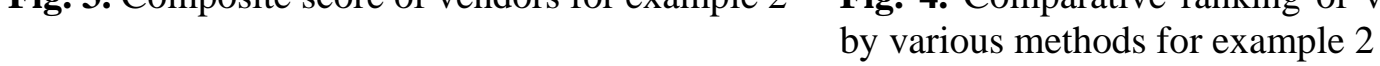

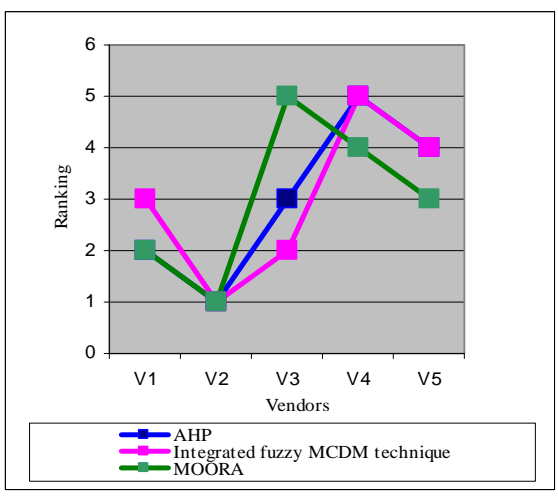




\subsection{Supplier selection (Example 3)}

A supplier selection inherently is a multi-criteria decision making problem and having a strategic dimension to any supply chain system. The selection decisions become difficult as the information in a vague environment are often imprecise and complex in nature. Expert's opinions play a major role in assessing these information in terms of linguistic variables and impart a fuzzy number on the basis of their human judgments (Table 13 \&14). The selection attributes of alternative suppliers often varies depending upon the type and nature of products of that particular chain. Here a numerical problem is extracted from Li et al. (2007) in order to demonstrate the applicability of MOORA in supplier selection. In the problem there are four alternative suppliers $S_{i}(i=1,2,3,4)$ primarily selected as alternatives and five attributes or criteria $C_{j}(j=1,2, \ldots, 5)$ are chosen for the decision making. The five attributes are reputation risk $\left(C_{1}\right)$, service quality $\left(C_{2}\right)$, product quality $\left(C_{3}\right)$, delivery time $\left(C_{4}\right)$, and price $\left(C_{5}\right)$ as shown in Table 14 . Among these attributes $C_{1}, C_{2}, C_{3}$ are to be maximized being the beneficial criteria where as $\mathrm{C}_{4}, \mathrm{C}_{5}$ are to be minimized being the non-beneficial criteria.

The fuzzy decision matrix comprising of performance measures of the alternatives with respect to all criteria as shown in Table 15. The performance rating of all the alternative vendors are defuzzified and shown in Table 16. In order to find the normalized performance rating, the best ratio system is chosen. For this best ratio system, the denominator is the square root of the sum of squares of each alternative supplier per criterion as shown in Table 16. The normalized values of performance rating of each alternative supplier with respect to all criteria are calculated by using Eq. (3) and shown in Table 17. The weights of all criteria are also shown in Table 17.

Composite Score of alternative suppliers are then calculated by using Eq. (5) as shown in Table 18. Fig. 5 depicts composite score of alternative suppliers. All the values of the composite score are positive in nature as the total number of beneficial criteria is larger than the non-beneficial criteria. The final ranking of the alternatives is determined on the basis of the descending order values of composite score. The ranking of suppliers according to the MOORA method is $S_{2} \succ S_{3} \succ S_{4} \succ S_{1}$ as shown in Table 18. The best supplier is $S_{2}$. Wu (2011) solved the same supplier selection problem of Li et al. (2007) by fuzzy TOPSIS with vague sets method and observed the ranking of suppliers as $S_{2} \succ S_{4} \succ S_{3} \succ S_{1}$. Fig. 6 shows a comparative ranking of alternative suppliers between MOORA and the method applied in Wu (2011). The ranking of the suppliers from these two methods reveal that the best supplier $\left(\mathrm{S}_{2}\right)$ and the worst supplier $\left(\mathrm{S}_{1}\right)$ remain same. But the ranking of the intermediate suppliers were different. Different methods resulted in different ranking of the intermediate suppliers. A comparative ranking analysis between these two methods is made and shown in Table 19.

\section{Table 13}

Linguistic variables and fuzzy numbers for the ratings of alternative suppliers

\begin{tabular}{ll}
\hline Linguistic variables & Fuzzy numbers \\
\hline Absolute Good (AG) & $(1,1)$ \\
Very Good (VG) & $(0.9,0.95)$ \\
Good (G) & $(0.8,0.9)$ \\
Fairly Good (FG) & $(0.7,0.85)$ \\
Medium Good (MG) & $(0.6,0.8)$ \\
Medium (M) & $(0.5,0.5)$ \\
Fairly Poor (FP) & $(0.3,0.45)$ \\
Poor (P) & $(0.2,0.3)$ \\
Very Poor (VP) & $(0.1,0.15)$ \\
Absolutely Poor (AP) & $(0,0)$ \\
\hline Source: Li et al.(2007) &
\end{tabular}


Table14

Decision makers opinion regarding attributes of supplier selection

\begin{tabular}{|c|c|c|c|c|c|}
\hline Suppliers $\left(S_{i}\right)$ & $\begin{array}{l}\mathrm{C}_{1} \text { (Reputation risk) } \\
(\mathrm{Max})(+)\end{array}$ & $\begin{array}{l}\mathrm{C}_{2} \text { ( Service Quality) } \\
(\mathrm{Max})(+)\end{array}$ & $\begin{array}{l}\mathrm{C}_{3} \text { (Product Quality) } \\
(\mathrm{Max})(+)\end{array}$ & $\begin{array}{l}\mathrm{C}_{4} \text { (Delivery Time) } \\
(\mathrm{Min})(-)\end{array}$ & $\mathrm{C}_{5}$ (Price) (Min)(-) \\
\hline $\mathrm{S}_{1}$ & FG & M & FG & VG & VG \\
\hline $\mathrm{S}_{2}$ & VG & FG & MG & M & MG \\
\hline $\mathrm{S}_{3}$ & G & VG & MG & G & FG \\
\hline $\mathrm{S}_{4}$ & VG & G & M & MG & VG \\
\hline
\end{tabular}

Table15

Fuzzy decision matrix of the alternative suppliers

\begin{tabular}{llllll}
\hline Suppliers & $\mathrm{C}_{1}(+)$ & $\mathrm{C}_{2}(+)$ & $\mathrm{C}_{3}(+)$ & $\mathrm{C}_{4}(-)$ & $\left.\mathrm{C}_{5}\right)(-)$ \\
\hline $\mathrm{S}_{1}$ & $(0.7,0.85)$ & $(0.5,0.5)$ & $(0.7,0.85)$ & $(0.9,0.95)$ & $(0.9,0.95)$ \\
$\mathrm{S}_{2}$ & $(0.9,0.95)$ & $(0.7,0.85)$ & $(0.6,0.8)$ & $(0.5,0.5)$ & $(0.6,0.8)$ \\
$\mathrm{S}_{3}$ & $(0.8,0.9)$ & $(0.9,0.95)$ & $(0.6,0.8)$ & $(0.8,0.9)$ & $(0.7,0.85)$ \\
$\mathrm{S}_{4}$ & $(0.9,0.95)$ & $(0.8,0.9)$ & $(0.5,0.5)$ & $(0.6,0.8)$ & $(0.9,0.95)$ \\
\hline
\end{tabular}

Table 16

Defuzzified performance score of alternatives with their sums of squares and square root values

\begin{tabular}{llllll}
\hline Suppliers & $\mathrm{C}_{1}(+)$ & $\mathrm{C}_{2}(+)$ & $\mathrm{C}_{3}(+)$ & $\mathrm{C}_{4}(-)$ & $\mathrm{C}_{5}(-)$ \\
\hline $\mathrm{S}_{1}$ & 0.775 & 0.5 & 0.775 & 0.925 & 0.925 \\
$\mathrm{~S}_{2}$ & 0.925 & 0.775 & 0.7 & 0.5 & 0.7 \\
$\mathrm{~S}_{3}$ & 0.85 & 0.925 & 0.7 & 0.85 & 0.775 \\
$\mathrm{~S}_{4}$ & 0.925 & 0.85 & 0.5 & 0.7 & 0.925 \\
Sum of Squares & 3.0344 & 2.4288 & 1.8306 & 2.3181 & 2.8019 \\
Square Roots & 1.7419 & 1.5584 & 1.353 & 1.5225 & 1.6739 \\
\hline
\end{tabular}

Table 17

Normalized and defuzzified rating of suppliers along with the weights of criteria

\begin{tabular}{|c|c|c|c|c|c|}
\hline Suppliers & $\mathrm{C}_{1}(+)$ & $\mathrm{C}_{2}(+)$ & $\mathrm{C}_{3}(+)$ & $\mathrm{C}_{4}(-)$ & $\mathrm{C}_{5}(-)$ \\
\hline $\mathrm{S}_{1}$ & 0.4449 & 0.3208 & 0.5728 & 0.6075 & 0.5526 \\
\hline $\mathrm{S}_{2}$ & 0.531 & 0.4973 & 0.5174 & 0.3284 & 0.4182 \\
\hline $\mathrm{S}_{3}$ & 0.488 & 0.5935 & 0.5174 & 0.5583 & 0.463 \\
\hline $\mathrm{S}_{4}$ & 0.531 & 0.5454 & 0.3695 & 0.4598 & 0.5526 \\
\hline Weights of criteria, $w_{j}$ & 0.196 & 0.272 & 0.184 & 0.217 & 0.131 \\
\hline
\end{tabular}

Source: Weights of criteria are extracted from Li et al.(2007)

Table 18

Composite score of alternatives and their ranking

\begin{tabular}{lllll}
\hline Suppliers & Benefit value & Non-Benefit value & Composite Score & Ranking \\
\hline $\mathrm{S}_{1}$ & 0.2799 & 0.2042 & 0.0756 & 4 \\
$\mathrm{~S}_{2}$ & 0.3345 & 0.126 & 0.2085 & 1 \\
$\mathrm{~S}_{3}$ & 0.3523 & 0.1818 & 0.1705 & 2 \\
$\mathrm{~S}_{4}$ & 0.3204 & 0.1722 & 0.1483 & 3 \\
\hline
\end{tabular}

Table 19

Comparative ranking of suppliers among various methods

\begin{tabular}{lll}
\hline Suppliers & Fuzzy TOPSIS with vague sets & MOORA (Applied method) \\
\hline $\mathrm{S}_{1}$ & 4 & 4 \\
$\mathrm{~S}_{2}$ & 1 & 1 \\
$\mathrm{~S}_{3}$ & 3 & 2 \\
$\mathrm{~S}_{4}$ & 2 & 3 \\
\hline
\end{tabular}




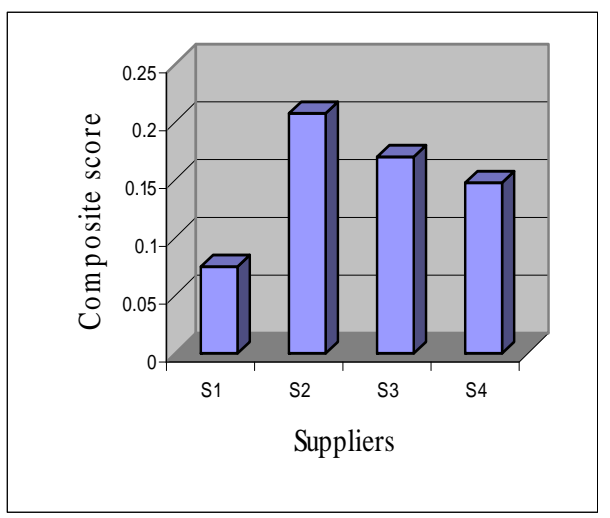

Fig. 5 Composite score of suppliers for example 3

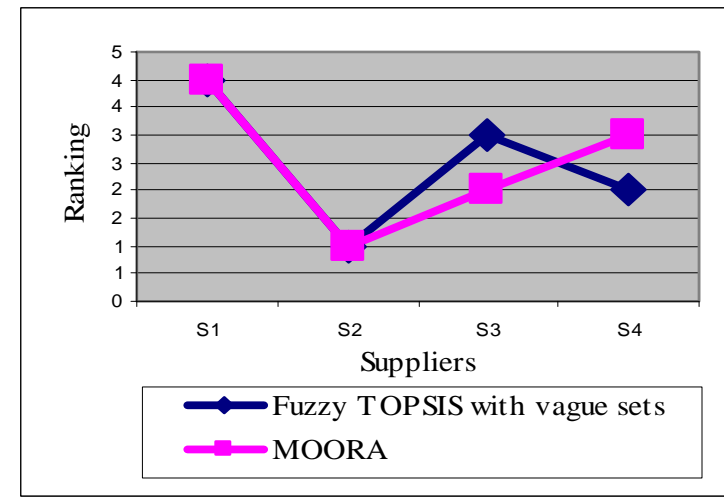

Fig. 6 Comparative ranking of suppliers obtained by various methods for example 3

\section{Conclusions}

Decision making for supply chain strategies under FMCDM environment involves complex evaluation process due to imprecise information. The complexity further increases as the number of alternatives and selection attributes increases. In this regard the application of the MOORA method is recommended for making decisions in a supply chain for the selection of best alternative from a number of alternatives. Three illustrative examples are considered to adjudge its enviable significance from the point of viability and feasibility. In example 1, it is observed that the ranking of all the alternatives obtained by applied method exactly match with those derived by the earlier researchers. In example 2, the ranking of the top two vendors exactly match with the result obtained from traditional AHP and MOORA method whereas the best vendor remains same among all the three methods. In example 3, the ranking of the suppliers obtained by MOORA and fuzzy TOPSIS with vague sets methods reveal that the best supplier and the worst supplier remain same. But the ranking of the intermediate vendors/suppliers were found different in example $2 \& 3$. The disparities among the intermediate rankings of the alternatives may be due to the diverse opinion given by the decision makers. The MOORA method can be applied in fuzzy environment considering both the qualitative as well as the quantitative criteria. Computationally the MOORA method is very simple and easily comprehensible which can handle large number of selection criteria. Application of this method in a wider range of selection problem in a supply chain is a direction of future research work.

\section{References}

Bhttacharya, A., Sarkar, B., \& Mukherjee, S.K. (2004). A new method for plant location selection: a holistic approach, International Journal of Industrial Engineering: Theory, application and practice, 11 (4), 330 - 338.

Brauers, W.K.M. (2004). Optimization methods for a stakeholder society, A revolution in economic thinking by multiobjective optimization, Boston: Kluer Academic Publishers.

Brauers, W.K.M., \& Zavadskas, E. K. (2006). The MOORA method and its application to privatization in a transition economy, Control and Cybernetics, 35, 445 - 469.

Brauers, W.K.M., Zavadskas, E. K., Peldschus, F., \& Turskis, Z. (2008). Multi-objective decisionmaking for road design, Transport, 23, 183 - 193.

Brauers, W.K.M., \& Zavadskas, E. K. (2009). Robustness of the multi-objective MOORA method with a test for the facilities sector, Technological and Economic Development of Economy: Baltic Journal on sustainability, 15, $352-375$.

Chen, C.T. (2001). A fuzzy approach to select the location of the distribution center, Fuzzy Sets and Systems, 118, 65-73. 
Chen, C. T., Lin, C. T., \& Huang, S. F. (2006). A fuzzy approach for supplier evaluation and selection in supply chain management, International Journal of Production Economics, 102, 289-301.

Chen, C.L., Yuan, T.W., \& Lee, W.C. (2007). Multi-criteria fuzzy optimization for locating warehouses and distribution centers in a supply chain network, Journal of the Chinese Institute of Chemical Engineers, 38, 393 - 407.

Chun,Y. S.,\& Kun, T. Y. (2009). A generalized fuzzy approach for strategic problems: The empirical study on facility location selection of authors' management consultation client as an example, Expert Systems with Applications, 36, 4709 - 4716.

Chu, T. C. (2002). Facility location selection using fuzzy TOPSIS under group decisions, International Journal of Uncertainty, Fuzziness and Knowledge-Based Systems, 10(6), 687-701.

Coyle, J. J., Bardi, E. J., \& Langley, C. J. (2003). The management of business logistics: A supply chain perspective, (seventh ed.), Thomson, South -Western.

De Boer, L., Labro, E., \& Morlacchi, P. (2001). A review of methods supporting supplier selection, European Journal of Purchasing and Supply Management, 7(2), 75-89.

Dubois, D., \& Prade, H.(1978). Operations on fuzzy numbers, International Journal of Systems Science, 9, 613-626.

Emanuel, M., Achille M., \& Hokey, M. (2005). Consolidating a warehouse network: A physical programming approach, International Journal of Production Economics, 97, 1-17.

Feng, C. M., \& Wang, R. T. (2000). Performance evaluation for airlines including the consideration of financial ratios, Journal of Air Transport Management, 6, 133-142.

Guneri, A.F., Cengiz, M., \& Seker, S. (2009). A fuzzy ANP approach to shipyard location selection, Expert Systems with Applications, 36, 7992 - 7999.

Hees, P., \& Siciliano, J. (1996). Management :Responsibility for performance, New York: McGrawHill.

Heizer, J., \& Render, B. (2004). Principles of operations management, New Jersey: Prentice-Hall.

Hwang, C.L., \& Yoon, K. (1981). Multiple attribute decision making methods and applications, New York: Springer-Verlag.

Jinxiang, G., Marc, G., \& Leon, F. M. (2007). Invited Review, Research on warehouse operation: A comprehensive review, European Journal of Operational Research, 177, 1-21.

Kahraman, C., Ruan, D., \& Ibrahim D.G. (2003). Fuzzy group decision-making for facility location selection, Information Sciences, 157, 135-153.

Keufmann, A.,\& Gupta, M.M., (1991). Introduction to Fuzzy Arithmetic: Theory and Application, New

York: Van Nostrand Reinhold.

Kumar, M., Vrat, P., \& Shankar, R. (2004). A fuzzy goal programming approach for vendor selection problem in a supply chain, Computers and Industrial Engineering, 46(1), 69-85.

Kuo, R. J., Chi, S. C., \& Kao, S. S. (1999). A decision support system for locating convenience store through fuzzy AHP, Computers \& Industrial Engineering, 37, 323-326.

Lee, H.L., \& Billington, C. (1992). Managing supply chain inventory: Pitfalls and opportunities, Sloan management review, 33(3), $64-67$.

Li, G., Yamaguchi, D., \& Nagai, M. (2007). A grey based decision making approach to the supplier selection problem. Mathematical and computer modeling, 46 (3-4), 573-581.

Liang, G.S., \& Wang, M.J.J.(1991). A fuzzy multi-criteria decision-making method for facility site selection, International Journal of Production Research, 29(11), 2313-2330.

Liang, G. S.(1999). Fuzzy MCDM based on ideal and anti-ideal concepts, European Journal of Operational Research, 112, 682-691.

Li, S.G., \& Kuo, X. (2008). The inventory management system for automobile spare parts in a central warehouse, Expert Systems with Applications, 34, 1144-1153.

Mikhailov, L. (2002). Fuzzy analytical approach of partnership selection in formation of virtual enterprises, Omega, 30(2), 393-401.

Peter, B., \& Marco, C. (2009). Warehouse design: A structured approach, European Journal of Operational Research, 193, 425-436. 
Sanayei, A., Mousavi, S. F., \& Yazdankhah, A. (2010). Group decision making process for supplier selection with VIKOR under fuzzy environment, Expert System with Applications, 37, 24 - 30 .

Shuo,Y. C., Yao, H. C., \& Chun,Y. S. (2008). A fuzzy simple additive weighting system under group decision-making for facility location selection with objective/subjective attributes, European Journal of Operational Research, 189, 132-145.

Shyur, H.J., \& Shih, H.S. (2006). A hybrid MCDM model for strategic vendor selection, Mathematical and Computer Modelling, 44(8), 749-761.

Simchi-Levi, D., Kaminsky, P., \& Simchi-Levi, E. (2003). Designing \& managing the supply chain, New York: McGraw-Hill.

Stevenson, W. J. (2005). Operations management, New York: McGraw-Hill.

Van Delft, A., \& Nijkamp, P. (1977). Multi-criteria Analysis and Regional Decision-making, Leiden: Martinus Nijhoff Publishers.

Wang, Y. J., Lee, H. S., \& Lin, K. (2003). Fuzzy TOPSIS for multi-criteria decision making, International Mathematical Journal, 3, 367-379.

Wang, Y. J., \& Lee, H. S. (2007). Generalizing TOPSIS for fuzzy multiple-criteria group decisionmaking, Computers and Mathematics with Applications, 53, 1762-1772.

Yang, J.L., Huan N. C., Gwo-Hshiung ,T., \& Ruey H.,Y. (2008). Vendor selection by integrated fuzzy MCDM techniques with independent and interdependent relationships, Information Sciences, 178, 4166-4183.

Zadeh, L.A. (1965). Fuzzy sets, Information and Control, 8, 338-353.

Zeleny, M. (1982). Multiple criteria decision making. New York: McGraw-Hill. 